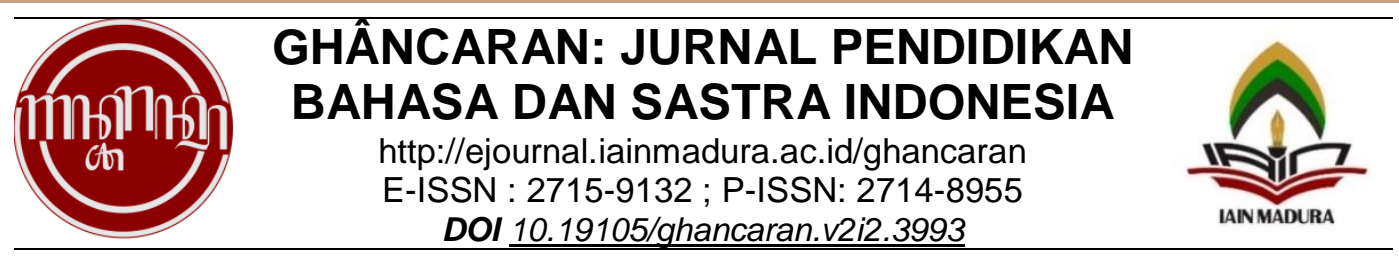

\title{
Bahasa Pengantar Peminjaman Uang Masyarakat Kampung Manten Kecamatan Kota Pamekasan
}

\author{
Nanang Ahmad Dahnan Sjafii \\ SMAN 1 Pademawu \\ Alamat surel: nanangahmaddhani@gmail.com
}

\begin{tabular}{ll}
\hline \hline & Abstrak \\
\hline Kata Kunci: & Bahasa memiliki peranan yang penting dalam komunikasi. \\
Komunikasi; & Komunikasi membutuhkan prinsip kerja sama yang baik. Namun, \\
perlokusi; & tidak semua kerja sama itu terjadi dengan baik dan lancar karena \\
bahasa & para pelaku komunikasi mengutarakan maksudnya dan ada pula \\
& yang tidak secara langsung mengutarakan maksud yang \\
& sebenarnya. Salah satu alat komunikasi yang senantiasa \\
& menyembunyikan maksudnya ialah perlokusi. Penelitian ini \\
& bertujuan memberikan gambaran tentang bahasa yang digunakan \\
& dalam meminjam uang. Peneliti menggunakan metode deskriptif \\
& untuk menganalisis data dan metode analisis dokumen untuk \\
& menganalisis dokumen yang telah terkumpul. Untuk memudahkan \\
& proses penganalisaan data, peneliti menggunakan metode \\
& transliterasi (menterjemahkan) data yang ada ke dalam bahasa \\
& Indonesia. Hasil penelitian ini menunjukkan bentuk kata-kata atau \\
& ujaran guna menarik simpati pemberi pinjaman, tindakan \\
& memberikan sesuatu kepada pemberi pinjaman, serta gesture \\
& (konteks) yang mendukung maksud yang dinginkan oleh peminjam \\
uang. &
\end{tabular}
uang.

\section{Keywords:} communication; perlocution; cooperation: language.

\section{Abstract}

In communication, language has a very important role. Each of the cooperation, not all kinds of the cooperation will happen smoothly because there is a direct communication which actors say the words, and some are not directly to express real intentions. One means of communication which always hides his point is perlocutions. Because this study aims to provide a picture of something, researcher used a descriptive method to analyze the data and document analysis method for analyzing a document that has been collected. In addition, both of these methods are expected researcher to facilitate the preparation of the report. to facilitate the process of analyzing the data, The researcher use the translation method the existing data into Indonesian. The results of this study have a form that can be in the form of words or utterances that can attract the sympathy of the lender and the act of giving something to the lender and gestures that support the intentions desired by the borrower.

Terkirim : 23-11-2020 ; Revisi: 18-12-2020 ; Diterima: 18-01-2021

(CGhâncaran: Jurnal Pendidikan Bahasa dan Sastra Indonesia

Tadris Bahasa Indonesia

Institut Agama Islam Negeri Madura, Indonesia 


\section{PENDAHULUAN}

Sebagai makhluk sosial, manusia akan bertindak ke arah yang lebih baik dalam kehidupan bermasyarakat secara luas. Hal ini dilakukan karena keinginan manusia sebagai pelaku sosial dalam masyarakat mencari sesuatu yang dapat digunakan sebagai alat pemenuhan kebutuhan hidupnya. Sering kali terjadi kesimpangsiuran penyampaian informasi dan pemenuhan kebutuhan setiap individu sebagai wujud interaksi dalam kehidupan sosial. Mujib (2015) menjelaskan bahwa manusia hadir ke dunia sebagai subjek yang memiliki kesadaran diri, tidak hanya hadir sebagai benda di dunia ini, melainkan sebagai subjek yang berpikir, berefleksi, dan bertindak secara kritis dan bebas. Sumarsono (2010) juga memaparkan bahwa setiap individu dapat bertingkah laku dalam wujud bahasa. Tingkah laku bahasa individu ini dapat berpengaruh luas pada anggota masyarakat bahasa yang lain. Namun, individu itu tetap terikat pada "aturan permainan" yang berlaku bagi semua anggota masyarakat.

Bahasa menjadi salah satu faktor keberhasilan komunikasi dalam kehidupan masyarakat. Bahasa juga memiliki fungsi yaitu alat komunikasi manusia (Chaer, 2010). Verawati \& Mulyadi (2019) menegaskan bahwa hal penting yang berkenaan dengan keberhasilan pengaturan interaksi sosial melalui bahasa adalah strategi-strategi yang mempertimbangkan status penutur dan mitra tutur. Interaksi manusia dalam bentuk bahasa akan tercapai apabila penutur dan mitra tutur saling memaham inti dari pembicaraannya.

Prinsip kerja sama memungkinkan seseorang peserta percakapan untuk berkomunikasi dengan asumsi bahwa peserta yang lain bersedia bekerja sama (Leech, 2016). Dalam hal ini, peserta percakapan telah memiliki keinginan untuk bekerja sama. Keadaan semacam ini merupakan salah satu cara manusia untuk memenuhi kebutuhannya. Kerja sama tersebut dilakukan dengan cara dan hasil yang berbedabeda. Dalam keadaan yang demikian itu, komunikasi menjadi faktor utama keberhasilan kerja sama yang dilakukan.

Komunikasi digunakan untuk menciptakan dan memupuk hubungan dengan orang lain. Komunikasi dapat berkembang dengan bertukarnya informasi yang dimiliki oleh setiap manusia. Tindakan komunikasi dapat dilakukan dengan berbagai macam cara. Ada yang dilakukan secara langsung seperti percakapan tatap muka dan yang dilakukan secara tidak langsung seperti komunikasi lewat medium atau alat perantara seperti surat kabar, majalah, radio, film, dan televisi. Dalam hal ini, anggota masyarakat melakukan tindak tutur untuk menyampaikan informasi dalam melengkapi kebutuhan akan interaksi dengan orang lain yang saling menguntungkan. Dengan kata lain, komunikasi akan berjalan sesuai keinginan apabila terjadi peristiwa tutur yang saling menguntungkan di antara pihak-pihak yang melakukan komunikasi.

Tindak tutur dalam peristiwa tutur merupakan dua gejala yang terjadi pada suatu proses yaitu proses komunikasi. Di dalam kehidupan manusia tidak bisa lepas dari peristiwa tuturan, karena dengan tuturan manusia dapat menyampaikan informasi kepada lawan tuturnya serta dapat dimengerti satu dengan yang lain. Tuturan atau tindak tutur itu beraneka ragam jenisnya salah satunya pengelompokkan berdasarkan sifat hubungannya yang di dalamnya mencakup tindak tutur lokusi, ilokusi, dan perlokusi. Masing-masing jenis tindak tutur ini memiliki karakteristik yang berbeda.

Austin (1975) dalam How to do Things with Words mengemukakan bahwa mengujarkan sebuah kalimat tertentu dapat dipandang sebagai melakukan tindakan (act), di samping memang mengucapkan kalimat tersebut. Austin membedakan tiga jenis tindakan yang berkaitan dengan ujaran, yaitu lokusi, ilokusi, dan perlokusi. Penjelasan tentang ketiga istilah ini lebih gamblang disampaikan oleh Putrayasa (2014) sebagai berikut (1) tindak lokusi, yaitu tindak tutur untuk menyatakan sesuatu, (2) tindak ilokusi, yaitu apa yang ingin dicapai oleh penuturnya pada waktu 
menuturkan sesuatu dan dapat merupakan tindalkan menyatakan, berjanji, minta maaf, mengancam, meramalkan, memerintah, meminta, dan lain sebagainya, (3) tindak perlokusi, yaitu tindakan untuk memengaruhi lawan tutur, seperti, memalukan, mengintimidasi, membujuk, dan lain-lain.

Penelitian tindak tutur perlokusi sudah pernah dilakukan sebelumnya. Pertama, Farrah Fitriah dan Siti Sarah Fitriani pernah melakukan penelitian berjudul Analisis Tindak Tutur dalam Novel Marwah di Ujung Bara Karya R.H. Fitriadi. Penelitian tersebut termasuk penelitian yang kompleks karena mendeskripsikan makna tindak tutur lokusi, ilokusi, perlokusi, jenis konteks tutur, dan penyampaian yang ada dalam novel tersebut (Fitriah \& Fitriani, 2017). Penelitian tersebut memang mengkaji tentang tindak tutur yang memiliki relevansi dengan penelitian ini. Namun, terdapat perbedaan pada objek kajian dan aspek-aspek yang dikaji.

Kedua, penelitian yang dilakukan Yayuk Sebtiana dan Lailli Etika Rahmawat berjuduli Tuturan Lokusi, Ilokusi, dan Perlokusi dalam Interaksi Pembelajaran Siswa Kelas VII di SMP Negeri 2 Jumapolo. Penelitian tersebut mendeskripsikan jenis tindak tutur, fungsi, dan implikasi pada pembelajaran siswa kelas VII SMP (Sebtiana \& Lailli Etika Rahmawati, 2019). Penelitian tersebut memiliki relevansi dengan penelitian ini pada sisi kajian pragmatik. Namun, letak perbedaannya pada objek dan tambahan implikasi hasil penelitiannya.

Ketiga, penelitian yang dilakukan Nurul Inayah Fauziah berjudul Tindak Perlokusi Terhadap Tindak Tutur Ekspresif Mengeluh (Kajian Pragmatik). Penelitian tersebut mendeskripsikan tindak tutur ekspresif yang memiliki makna mengeluh (Fauziah, 2019). Untuk mengetahui tindak tutur perlokusi dalam hal mengeluh, penelitian tersebut menggunakan teori dari Levinson. Hal inilah yang menjadi perbedaan dengan penelitian ini yang menggunakan prinsip dari Austin. Selain itu, terdapat pula perbedaan pada sisi objek kajiannya.

Keempat, penelitian yang dilakukan oleh Muhammad Saepullah berjudul Tindak Tutur llokusi dan Perlokusi Antara Penjual dan Pembeli Di Pasar Modern Bintaro Jaya. Penelitian tersebut memaparkan percakapan penjual dan pembeli dalam negosiasi di pasar (Saepullah, 2019). Penelitian tersebut memiliki kesamaan pada sisi kajian pragmatik, sedangkan perbedaannya terletak pada objek kajian. Selain itu, penelitian yang dilakukan oleh Saepullah mengkaji dengan tindak tutur ilokusi dan perlokusi.

Bahasa pengantar peminjaman uang ini memiliki kekhasan dalam penyampaian dan penyembunyian makna (perlokusi) dalam setiap penyampaian maksud dari si peminjam uang kepada pemberi pinjaman. Oleh sebab itu, tujuan dalam penelitian ini ada dua yaitu, memberikan gambaran bentuk penyampaian perlokusi dan memberikan gambaran penyembunyian makna dalam setiap penyampaian pesan pada proses peminjaman uang. Jadi, penelitian ini masih memiliki korelasi dengan penelitian yang telah dilaksanakan sebelumnya dengan objek kajian yang berbeda.

\section{METODE}

Penelitian ini tergolong dalam penelitian interpretatif kualitatif. Interpretatif berarti mencari atau menterjemahkan maksud yang tersembunyi. Dalam hal ini terkait dengan perlokusi yang muncul dalam pengantar peminjaman uang. Sedangkan kualitatif menyajikan data yang dikumpulkan bukan berupa angka-angka, melainkan data tersebut berasal dari teks/naskah wawancara, catatan lapangan, dokumen pribadi, catatan memo, dan dokumen resmi lainnya.

Basrowi (2008) menyatakan bahwa sumber data utama dalam penelitian kualitatif adalah kata-kata dan tindakan selebihnya adalah data tambahan seperti dokumen dan observasi. Arikunto (2019) berpendapat bahwa sumber data dalam penelitian adalah subjek darimana data dapat diperoleh. Artinya, data yang diperoleh bersumber dari 
sumber data yang valid. Sumber data dalam penelitian ini yaitu tuturan atau bahasa yang digunakan seseorang dalam meminjam uang.

Prosedur pengumpulan data yang dilakukan dengan teknik simak libat cakap observasi. Pada metode simak-catat dan simak-rekam, peneliti menggunakan alat perekam tersembunyi seperti gawai yang disembunyikan di saku sehingga hasil yang didapat adalah sesuatu yang alami dan sesuai dengan prosedur pengumpulan data. Selanjutnya, hasil rekaman dicatat dan dialihbahasakan dari bahasa Madura ke dalam bahasa Indonesia sehingga pemerhati bahasa bisa memahami data yang disajikan peneliti. Selain itu, teknik wawancara juga digunakan untuk mendapatkan data yang sesuai. Wawancara dilakukan kepada orang-orang yang pernah terlibat dalam proses peminjaman uang.

Analisis data adalah proses pelacakan dan pengaturan secara sistematis transkrip wawancara, catatan lapangan, dan bahan-bahan lain yang dikumpulkan untuk meningkatkan pemahaman terhadap bahan-bahan tersebut agar dapat dipresentasikan semuanya kepada orang lain (Syamsuddin \& Damianti, 2006). Selanjutnya, Sudaryanto (1993) menegaskan bahwa menganalisis berarti tindakan penanganan langsung dari peneliti tentang masalah yang terkait dengan data, yaitu dengan cara mengurai dan memburaikan masalah yang bersangkutan dengan cara tertentu. Analisis data dalam penelitian ini dilakukan dengan cara mentranskrip data yang diperoleh (mayoritas berbahasa Madura ke dalam bahasa Indonesia), mengklasifikasikan data sesuai dengan teori dan tujuan penelitian, dan interpretasi data. Penelitian inj berlokasi di kampung Manten, Kecamatan Kota Pamekasan dengan jangka waktu pengambilan sampel penelitian mulai Desember 2019 sampai dengan Juli 2020. Jangka waktu penelitian ini tergolong lama karena tidak setiap hari ditemukan peminjam uang yang datang.

\section{HASIL DAN PEMBAHASAN}

Penelitian ini bertujuan untuk memberikan gambaran bentuk perlokusi yang muncul pada setiap dialog yang diucapkan oleh peminjam uang dan wujud penyembunyian makna yang dilakukan oleh peminjam uang untuk mendapatkan hasil sesuai keinginannya. Namun, tidak semua proses peminjaman uang ini berhasil dan sukses. Ada kegagalan yang diperoleh oleh peminjam walaupun dialog peminjam didukung dengan gesture yang sangat mendukung maksud yang diinginkan peminjam uang seperti memelas, menangis, dan yang lain.

Berikut hasil dan pembahasan sesuai data yang diperoleh berdasarkan dialogdialog yang dilakukan. A berperan sebagai peminjam uang dan B sebagai pemberi pinjaman. Dialog berikut ini menunjukkan penggunaan bentuk perlokusi dengan sikap.

A : lye Buk, sengko' etaghi oreng. (lya, Kak saya ditagih orang)

$B$ : E taghi da'remma (Ditagih orang gimana?)

A : Bakto tang ana' maso' ma sake', sengko aotang ka oreng. Sateya etaghi. Otangnga du juta. Embuk Andhi'? (Waktu anak saya masuk rumah sakit, saya utang sama orang. Sekarang, dia nagih ke saya. Utangnya dua juta...Kakak punya??)

B : Addu saporana bhai ye. Kaka' an be'en sateya reya butuh bannya' pesse keya. Ye...maaf bhai sengko ta' bisa abhanto. (Aduh maaf ya... Mas kamu sekarang lagi butuh uang banyak juga. Jadi, maaf ya...saya gak bisa bantu.)

Dalam dialog tersebut, peminjam uang menceritakan keadaan dirinya yang ditagih orang karena pernah meminjam uang untuk keperluan biaya pengobatan di rumah sakit. Kenyataan ini diharapkan peminjam dapat menimbulkan rasa empati pemberi pinjaman untuk memberikan sejumlah uang. Namun, harapan memperoleh uang yang diinginkan tidak bisa tercapai karena pemberi pinjaman juga butuh uang untuk keperluan keluarganya. Dari uraian tersebut, peneliti menemukan bahwa perlokusi yang diharapkan peminjam uang pun tidak berhasil karena pemberi pinjaman juga 
membutuhkan uang untuk keperluan studi suaminya. Peminjam uang mengalami kegagalan dalam usahanya mendapatkan sejumlah uang dari kakaknya. Temuan yang sama didapatkan berupa janji si peminjam uang kepada orang yang akan dipinjami untuk membayar utangnya pada jangka waktu tertentu. Berikut dialognya.
A : Da'neka Mas Nanang. Potrana kaule maso'roma sake'. Kaule pon a lenteng ka man ka'emman tape tettep ta' olle. Ta'oneng pon mon ta'olle pole deri ka'dinto pas nyare ka'dimma pole ( Gini Mas Nanang. Anak saya masuk rumah sakit. Saya sudah cari ke mana-mana tapi belum dapat juga. Gak tahu deh jika dari sini saya juga belum dapat lalu saya cari kemana lagi).
$B$ : Kadhi ponapa ghi...kaule aberri'e tape kaule bhuto jughen. Tape ta'napa pon sampeyan angghuy gellu pola ma' kaule bede rajekke laen (Gimana ya..? saya juga butuh sebenarnya tapi gak apa-apa deh sampeyan pake dulu mungkin saya ada rejeki yang lain)
A : Sakalangkong Mas ghi..Moghe ekatarema'a amalla sampeyan.... (Terima ksih ya Mas.. Semoga amal sampeyan ini diterima)
$B$ : Neka obangnga moghe dhuli sae potrana sampeyan.. (Ini uangnya semoga putra sampeyan cepat sembuh).
A : Engghi Mas..Samenggu agghi' epabeliye (lya Mas satu minggu lagi saya kembalikan) (07)
$B$ : Engghi pon.... (lya lah)

Dalam dialog ini, peminjam menceritakan kesulitan yang dialaminya, yaitu putranya masuk rumah sakit dan peminjam telah berusaha meminjam uang ke orang lain, tetapi belum mendapatkan uang yang diharapkan. Kenyataan ini diharapkan mendapatkan rasa iba dari pemberi pinjaman untuk memberikan sejumlah uang. Dari uraian tersebut, ditemukan bahwa perlokusi yang diharapkan peminjam uang pun berhasil karena pemberi pinjaman memberikan sejumlah uang untuk peminjam dengan diiringi doa semoga putra peminjam cepat sembuh dan peminjam berjanji untuk mengembalikan uang tersebut satu minggu berikutnya. Pada dialog yang lain, terdapat perlokusi yang diterapkan berupa janji membayar utang dalam waktu secepatnya. Hal tersebut terdapat pada dialog berikut.
A : Ta'tao wa' Matun ghigir polana sengko masang paralon dari romana Anna ka leke e ada'en roma maso' ka bates tanana ca'en. Lesso sengko ka oreng settong jiye.....Gak tahu si Matun tuh marah-marah karena saya masang paralon untuk saluran air dari rumah Anna ke selokan depan rumah katanya masuk batas tanahnya. Saya capek pada orang itu)..
$B$ : Oreng nga' rowa ta'kera aobe mon ta' dhele mate (Manusia seperri itu takkan berubah samai dia mati)
A : Mara mon bede sengko' ngenjamma pessena lema juta bhei tang bates tana epagara perreng bhei ma'le ta' ngaroweng pole. Dhina ma' romana petteng ta' nemmo mata are (Kalau ada saya mau pinjam uangnya lima juta saja nanti saya pagari bambu saja sampai batas tananh saya biar gak marah-marah lagi)
$B$ : Bila parlona..?. (Kapan perlunya ?)
A :Ye mon bisa lagghu' polana tokangnga la siap se alakowa (Kalau bisa besok malam karena tukangnya sudah siap bekerja)
$B$ : lye la kala' lagghu' malem (lya sudah ambil saja besok malam))
A :Sakalangkong ye...sengko.pas terrosa ta' bid-abid.se penting la pade bares(Terima kasih ya... saya langsung pamit pulang yang penting semua sehat)
$B$ : lye la te-ngate. (lya hati-hati di jalan).

Peminjam menceritakan bahwa tetangganya (Matun) marah-marah karena peminjam memasang saluran air di samping rumah tetangganya. Hal ini yang menjadikan peminjam ingin membuat pagar yang permanen agar tidak terganggu lagi oleh tetangganya tersebut. Salah satu cara yang ditempuh oleh peminjam uang adalah meminjam uang untuk mewujudkan kebutuhan tersebut. Perlokusi yang diharapkan peminjam uang pun berhasil karena pemberi pinjaman memberikan sejumlah uang untuk peminjam. Selanjutnya, peminjam berjanji untuk mengembalikan uang tersebut secepatnya. Kejadian yang sama juga terjadi pada dialog berikut. 
A : Tao mara...ja' ngoca'a engko' nyareaghi ano ka na'-kana' kemma pola andi' juko' ta' la ce' nyamanna. Mon neng-enneng man-ta' nyamaan eber deggi' ca'an pas ngoca' la ta' eddi'. Juko' tempe tahu. Tempe tahuna Atun se melle. Juko cakalanna tello biggi' ne'-kene' tello polo ebu. Ja' la sateya be'en. (Gak tahu deh...kalau saja bila saya carikan anu ke anak-anaknya mungkin punya lauk kan enak. Katanya enak dan tidak enaknya selera tapi nanti bilang sudah tak kuat ngunyah lagi makanannya. Lauk tahu tempe. Tahu tempenya atun yang belikan. Ikan cakalang tiga ekor kecil-kecil tiga puluh ribu. Biasalah jaman sekarang.)

$B$ : Samangken ngenjamma sanapa bu Errum ? (Sekarang mau pinjam berapa bu Rum?)

A : Seket ebu bhai la ja' nya'-bannya'(Lima puluh ribu saja lah jangan banyak-banyak).

$B$ : Neka pa'polo ebu bhai..(Ini empat puluh ribu saja)

Dari dialog tersebut, peminjam uang tidak langsung mengatakan maksud sebenarnya, tetapi peminjam cenderung untuk mengutarakan sebab-sebab peminjam itu ingin meminjam uang. Di awali dengan keluh kesah peminjam yang ditagih orang sampai pada latar belakang mengapa peminjam uang tersebut ditagih orang. Dengan kata lain, sebab sebenarnya tidak dikatakan terlebih dahulu melainkan sebab yang tidak ada kaitan sama sekali dengan keinginannya untuk meminjam uang. Bentuk perlokusi disertai dengan nada yang meninggi dan menunjukkan kekesalan kepada suaminya yang memiliki permintaan yang beragam dan tidak disesuaikan dengan keadaan keuangan keluarga. Rasa kesal yang dialami oleh peminjam dapat meluluhkan hati pemberi pinjaman untuk memberikan sejumlah uang sesuai kesepakatan kedua belah pihak. Perlokusi yang diharapkan peminjam uang pun berhasil karena pemberi pinjaman memberikan uang kepada peminjam. Pada dialog yang lain terdapat juga kiat peminjam untuk menarik simpati pemberi pinjaman. Perhatikan dialog berikut.

\begin{abstract}
A : Be'en ta'terro andhi'e motor (kamu gak ingin punya mobil?)
B : Saporana saos ta' karep gi'en (Maaf belum ada keinginan.)

$\boldsymbol{A}$ : Enja' rapa je' roma la mare, garasi la bede, kare motorra reya polana tang motor wa' bede se naber tape sengko'ghi' eman se epakalowarra. Ma'pola be'en terro nganguyya ta'rapa wa' tang andhi sabe' dinna pas la angguy sakencengnga tape sataon ekala'a pole so sengko' sabeb sengko' ta' terro motor gella' eteggu' oreng se ta' open. Pola ma'kareb dhina la pesse'e pa'polo juta sengko' ghun menta bakto sataon kaangguy alonasen cecelan ka diller sataon reya. Mare jiye so sengko' otangnga e serra'enna motor ekeba'e pole ka tang bengko. Selama sataon jiye angguy terserra be'en. Anggp la andhi'en be'en dibi' (Rumahmu kan sudah jadi, garasi sudah ada, tinggal mobilnya karena mobil saya ada yang nawar tapi saya belum mau melepasnya. Mungkin kamu ingin pakai mobil itu terserah. Itu mobil saya letakkan di sini kamu boleh pakai sesuka hati kamu tapi satu tahun akan saya ambil lagi karena saya tidak ingin mobil itu jatuh ke tangan yang salah. Kalau kamu ingin tidak apa-apa ganti dengan uang empat puluh juta saya hanya minta waktu satu tahun untuk pelunasan cicilan ke dealer setahun ini. Setelah itu, utang saya bayar mobil saya bawa pulang lagi.Selama satu tahun itu kamu pakai deh terserah kamu. Anggap mobilmu sendiri)
\end{abstract}

B : Oreng la kareb ma'e paksa'a. Saparona saos ghi... .(Saya tidak ada keinginan kok dipaksa. Maaf saja)

A : Benni e paksa tape eman berengga ghi' genteng ta'rogi la mon e sabe' dinna' ( Bukannya maksa tapi eman mobilnya masih bagus gak akan rugi kalau ada di sini)

B : Napa pole kaule soro pesse'e pa'polo juta sampeyan nyaba' ka' dinto gratis ebaghiye dhe' kaule, kaule ta' kera endha'. (Jangankan uang empat puluh juta saya harus ganti, gratispun mobil itu sampeyan berikan ke saya, saya gak akan mau)

A : Ye dhina la mon tade' pa'polo juta. Sengko' ngenjemma lema juta bhei. (Ya sudah kalau tidak ada empat puluh juta. Saya mau pinjam lima juta saja)

B : Barampa ? sajuta? (Berapa? Satu juta?)

A : lye la mara ko' keng entarra ka songennep laggu' ta' andhi ongkos.(lya deh karena saya mau ke sumenep besok gak punya ongkos)

B : Ya' sajuta bhei tape dhuli pabeli tanda tangan kuitansi neka . (ini satu juta saja tapi cepat kembalikan tanda tangan kuitansi ini).

A : Duh ma' gawat iye la..(Kok gawat nih mana.)

B : Pa sasuai so bakto palonasan neng e kuitansi mon lopot palang sampeyan (Sesuaikan dengan waktu pelunasan di kuitansi kalau tidak celaka kamu) 
A : lye paste elonasen so sengko'..Assalamu'alaikum (Pasti saya lunasi sesuai waktu.Assalamu'alaikum.)

B : Wa'alaikum salaam

Peminjam menceritakan bahwa dia memperbolehkan mobilnya dijadikan jaminan untuk mendapatkan pinjaman uang. Hal ini dilakukan peminjam untuk menyindir secara halus kepada pemberi pinjaman bahwa mobil itu boleh dipakai oleh pemberi pinjaman asalkan peminjam dapat meminjam sejumlah uang yang diinginkan. Peminjam tidak dapat menumbuhkan rasa iba pada pemberi pinjaman karena pemberi pinjaman hanya memberikan uang lebih sedikit dibandingkan uang yang diinginkan peminjam. Pada akhirnya, pemberi pinjaman lebih hati-hati tentang pelunasan uang pinjaman dengan cara memberikan kuitansi kepada peminjam uang untuk menentukan batas atau tempo pelunasan yang disepakati kedua belah pihak. Hal ini dilakukan pemberi pinjaman karena peminjam selalu tidak sesuai waktu pelunasan dengan kesepakatan yang telah ada sehingga kuitansi tersebut dapat dijadikan bukti kesepakatan bagi peminjam untuk melunasi utangnya. Dengan demikian, peminjam diharapkan dapat melunasi utangnya sesuai waktu yang ditentukan.

Perlokusi yang diharapkan peminjam uang pun berhasil karena pemberi pinjaman memberikan sejumlah uang untuk peminjam walaupun tidak sesuai keinginan peminjam dan peminjam terkejut karena pemberi pinjaman menyodorkan kuitansi untuk kesepakatan pelunasan utang. Dengan terpaksa, peminjam menandatangani kuitansi tersebut karena peminjam tidak dapat mengelak untuk tidak melunasi utangnya. Dalam dialog tersebut, peminjam berhasil mendapatkan uang sesuai keinginannya. Namun, pemberi pinjaman memberikan bukti kuitansi agar peminjam tidak meleset dalam pelunasannya. Selain itu, perlokusi yang ditunjukkan dengan kata-kata bisa juga maksud tersembunyi. Hal itu dilakukan dengan menawarkan jasa untuk pemberi pinjaman agar peminjam bisa mendapatkan pinjaman sesuai keinginannya. Berikut ini disajikan dialognya. Dialog lain yang menjadi kiat peminjam uang adalah sebagai berikut.

$B$ : Napa neka (Apa ini))

A : Napa gun berras pola ma' bosa ekalammban atana' degghi'. (Hanya beras kok mungkin bisa dimasak nanti) (15)

$B$ : Bede napa Nyah?. (Ada apa Bibi?).

A : Ano..sera pon ka' dissa.. Asip laggu' alamarra na'-kana'. Namong neka bulan towa. Da'remma ghi? (.Anu siapa itu ya.. si Asip mau melamar cewek besok, tapi ini kan bulan tua. Bagaimana ya?).

$B$ : Se seggut lebat ka'dissa ghi...? (Yang sering lewat itu ya?)

$A$ : Engghi..lerres.(lya betul)

$B$ : Na'-kana' ka' dimma ka'dissa? (Anak mana dia?)

A : Na'-kana' Kolpajung sae ghi..?.(Anak Kolpajung gimana dia?).

$B$ : Deddi ta' bisa nantos gajian sakale?(Jadi gak bisa nunggu gajian sekalian?)

$A$ : Asibba ta' poron pak!. (Asipnya gak mau Pak!)

$B$ : E..ta' oneng manabi saneka. Bila neka laggu' sore otaba saceppedda ghi? (Kapan ini dikembalikan besok sore atau secepatnya ya..?)

A : Engghi pas kaula majarra PDAM sakale...Sadhaja pa'ratos Pak..(lya lalu saya mau bayar PDAM sekalian..Semuanya empat ratus Pak)

$B$ : Neka' obangga. Pas bitong tako ta'genna'. (Ini uangnya lalu dihitung takut tidak pas)

Dalam dialog tersebut, peminjam uang sengaja memberikan sesuatu kepada pemberi pinjaman (kacang hijau) untuk diberikan kepada anggota keluarga pemberi pinjaman. Pemberi pinjaman sengaja bertanya untuk mengetahui alasan peminjam membawa sesuatu dari rumahnya dan kalimat berikutnya disampaikan alasan mengapa peminjam membawa sesuatu itu dari rumah. Ternyata, hal ini berhasil menggugah pemberi pinjaman untuk memberikan sejumlah uang sesuai kesepakatan. Perlokusi 
yang diharapkan peminjam uang pun berhasil karena pemberi pinjaman memberikan uang kepada peminjam dengan kesepakatan pengembalian uang pinjaman itu secepatnya.

Perlakuan lain yang ditunjukkan oleh peminjam adalah dengan perbuatan yang mengundang rasa iba pemberi pinjaman. Misalnya dengan berpura-pura sedih sampai menangis di depan pemberi pinjaman.
A : Kaule ghi'buru entar ka Andi nagi pesse sajuta satengnga. Lamba'gabay pessena DP sapeda motor. (Saya baru saja ke rumah Andi nagih uang satu juta setengah. Dulu sebagai DP sepeda motor) (05)
$B$ : Olle? (Dapat..)
A : Ta'olle. Kaule sampe nanges se menta tape egigiri so Andi.Kaule mole mbak terros ka'dinto. (Dak dapat. Saya sampai nangis untuk minta uang itu tapi dimarahi sama Andi. Saya pulang terus ke sini.)
$B$ : Terros anapa'a sampeyan? (Terus mau apa sampeyan?)
A : Roni ka'dissa sake Tipes e Malang terro moleya tape ta'andhi'pesse. Rojib gajian samenggu agghi' pas epabaliye so kaule (Roni itu sakit Typus di Malang ingin pulang tapi tak punya uang. Rojib gajian seminggu lagi lalu saya kembalikan)
$B$ : Ampon ja'nanges. Sanapa?. (Sudah gak usah nangis. Mau pinjam berapa?..).
$A$ : Satos ebu mbak Indah e keremma ka Roni e Malang pas soro mole.(Seratus ribu mbak Indah saya kirim ke Roni di Malang lalu saya suruh pulang.)
$B$ : Neka' moga dhuli sae Roni (Ini ..Semoga cepat sembuh Roni)

Penegasan tentang tindakan menangis peminjam memiliki maksud tertentu. Hal inilah yang dapat menimbulkan rasa iba dan kasihan dari pemberi pinjaman untuk memberikan sejumlah uang yang disepakati kedua belah pihak. Perlokusi yang diharapkan peminjam uang pun berhasil karena pemberi pinjaman memberikan uang kepada peminjam dengan kesepakatan pengembalian uang pinjaman seminggu berikutnya.

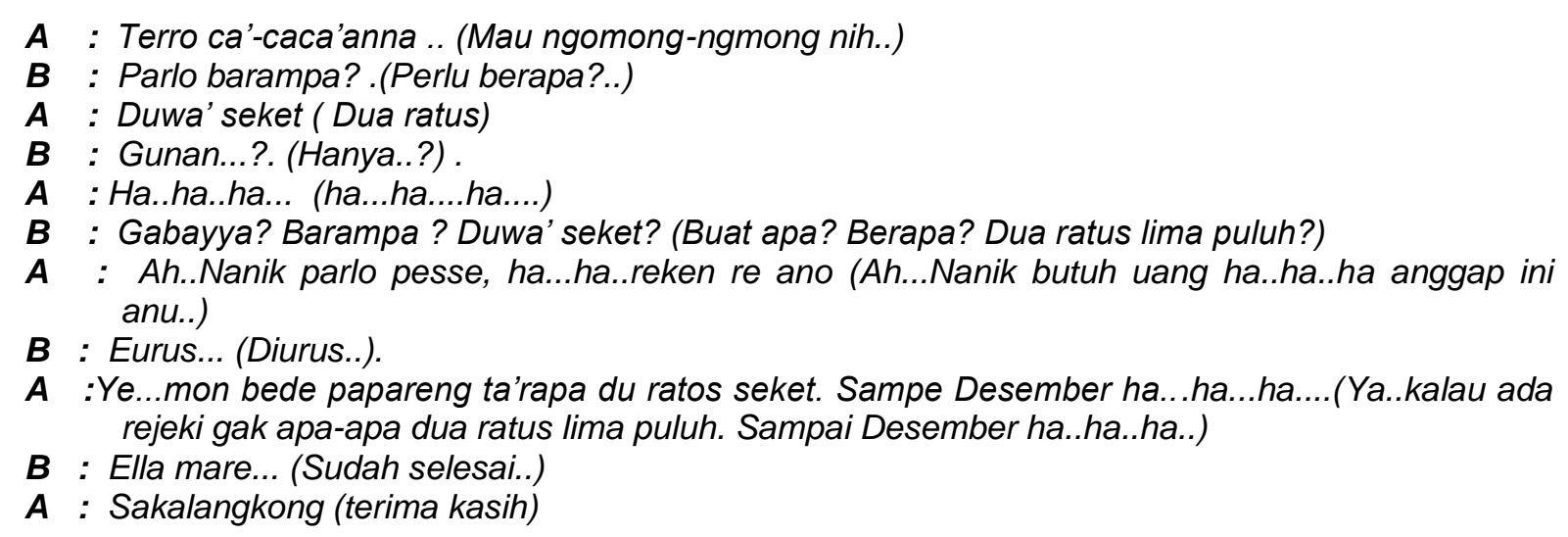

Pada dialog tersebut mendeskripsikan bahwa peminjam menceritakan alasan kepada pemberi pinjaman bahwa anaknya membutuhkan uang untuk keperluan yang tidak jelas tetapi pemberi pinjaman sudah memahami gelagat peminjam yang merasa malu dan tertawa agar tidak kentara dalam mengutarakan maksudnya. Peminjam beranggapan kalau pemberi pinjaman dapat mengatasi masalahnya. Peminjam juga sambil tertawa-tawa untuk menutupi rasa malunya. Pemberi pinjaman akhirnya memberikan uang yang jumlahnya sesuai keinginan peminjam uang karena pemberi pinjaman sudah mengetahui maksud peminjam dari sebelumnya. Peminjam uang juga berjanji melunasi utangnya pada waktunya. Perlokusi yang diharapkan peminjam uang pun berhasil karena pemberi pinjaman memberikan uang kepada peminjam walaupun jumlah uang tidak sesuai dengan keinginan peminjam. Bentuk perlokusi yang lain terdapat pada dialog berikut. 
A : Ano mbak Indah de'remma ngoca'en ye...ko'todus tape ko'buto ongghuwan. (Anu mbak Indah gimana ya ngomongnya saya malu tapi saya sangat butuh)

$B$ : La ngoca'rapa pola engko' bisa abanto (Sudah bilang saja mungkin saya bisa bantu)

A : Da'iye re. Sengko' melleya tana e temorra roma. Pesse korang seket juta. Be'en andhi ye. Minggu dateng epabaliye polana sengko' la ngala'bank tape cair minggu dateng. Se andhi' tana menta du are agghi' pessena. (Gini lo..Saya beli tanah di sebelah timur rumah. Uangnya kurang lima puluh juta. Kamu punya? Minggu depan saya kembalikan karena saya sudah ambil pinjaman bank tapi minggu depan cair, sedangkan yang punya tanah minta uangnya dua hari lagi uangnya)

$B$ : Sengko'ta'andhi' pesse sajiye mbak. Mon sapolo juta bede. (Kalau uang sebanyak itu saya gak punya tapi kalau sepuluh juta ada.)

Pada dialog tersebut peminjam uang memberikan kepastian bahwa uang pinjamannya akan dikembalikan dalam waktu yang pasti karena peminjam merasa memiliki jaminan uang yang sepadan dengan jumlah uang yang telah dipinjamnya. Ini juga merupakan cara peminjam untuk mendapatkan pinjaman uang sesuai kesepakatan akhir dari kedua belah pihak.

Dari uraian tersebut menunjukkan bahwa perlokusi yang diharapkan peminjam uang pun berhasil karena pemberi pinjaman memberikan sejumlah uang untuk keperluan keluarga peminjam uang dengan syarat uang pinjaman dikemblikan secepatnya. Namun, jumlah uang yang diharapkan peminjam lebih sedikit daripada harapan peminjam.

\section{SIMPULAN}

Dari hasil dan pembahasan yang telah dipaparkan dapat disimpulkan bahwa perlokusi yang terdapat pada bahasa pengantar peminjaman di masyarakat kampung Manten Kecamatan Kota Pamekasan memiliki bentuk yang dapat berupa kata-kata atau ujaran yang dapat menarik simpati pemberi pinjaman untuk meminjamkan sejumlah uangnya. Perlokusi yang digunakan sebagai pengantar peminjaman uang mayoritas dengan cara bercerita terlebih dahulu tentang kondisi yang dialami. Hal ini sebagai modal awal untuk menarik minat dan simpati pemberi utang. Bentuk penyembunyian makna dapat dilakukan dengan tindakan memberikan sesuatu kepada pemberi pinjaman dan gesture yang mendukung maksud yang diinginkan oleh peminjam uang. Namun, perlokusi yang dilakukan peminjam uang tidak selamanya mendapatkan hasil maksimal karena pemberi pinjaman tidak serta merta memberikan sejumlah uang diharapkan oleh peminjam. Dalam hal ini, peminjam tidak berhasil mendapatkan keinginannya atau disebut juga gagal dan tidak sesuai dengan keinginannya.

\section{DAFTAR RUJUKAN}

Arikunto, S. (2019). Prosedur Penelitian. Rineka Cipta.

Austin, J. L. (1975). How to Do Things with Words. Oxford University Press.

Basrowi, S. (2008). Memahami Penelitian Kualitatif. Rineka Cipta.

Chaer, A. dan L. A. (2010). Sosiolinguistik: Perkenalan Awan. Rineka Cipta.

Fauziah, N. I. (2019). Tindak Perlokusi Terhadap Tindak Tutur Ekspresif Mengeluh

(Kajian Pragmatik). Jurnal Sastra - Studi IImiah Sastra, 9(1), 29-48.

http://45.118.112.109/ojspasim/index.php/sastra/article/view/158

Fitriah, F., \& Fitriani, S. S. (2017). Analisis Tindak Tutur dalam Novel Marwah di Ujung

Bara Karya R.H. Fitriadi. Master Bahasa, 5(1), 51-62. http://e-

repository.unsyiah.ac.id/MB/article/view/11078

Leech, G. N. (2016). Principles of Pragmatics. Routledge.

Mujib, A. (2015). Pendekatan Fenomenologi dalam Studi IslaM. Jurnal Pendidikan

Islam, 6(2), 167-183.

http://www.ejournal.radenintan.ac.id/index.php/tadzkiyyah/article/view/1485 
Putrayasa, I. B. (2014). Pragmatik. Graha Ilmu.

Saepullah, M. (2019). Tindak Tutur Ilokusi dan Perlokusi Antara Penjual dan Pembeli Di Pasar Modern Bintaro Jaya. Universitas Pamulang.

Sebtiana, Y., \& Lailli Etika Rahmawati. (2019). Tuturan Lokusi, Ilokusi, dan Perlokusi dalam Interaksi Pembelajaran Siswa Kelas VII di SMP Negeri 2 Jumapolo [Universitas Muhammadiyah Surakarta]. http://eprints.ums.ac.id/71184/

Sudaryanto. (1993). Metode dan Aneka Teknik Analisis Bahasa: Pengantar Penelitian Wahana Kebudayaan Secara Linguistis. Duta Wacana University Press.

Sumarsono. (2010). Pragmatik. Universitas Pendidikan Ganesha.

Syamsuddin, A. R., \& Damianti, V. S. (2006). Metode Penelitian Pendidikan Bahasa. Diterbitkan atas kerjasama Program Pascasarjana Universitas Pendidikan Indonesia dengan Remaja Rosdakarya.

Verawati, F., \& Mulyadi, M. (2019). Tindak Tutur Masyarakat di Desa Lawangan Daya Kecamatan Pademawu Kabupaten Pamekasan. GHANCARAN: Jurnal Pendidikan Bahasa Dan Sastra Indonesia, 1(1), 51. https://doi.org/10.19105/ghancaran.v1i1.2984 